\title{
Molecular Methods in Clinical Microbiology Introduction
}

\section{DEBORAH JOSKO}

\section{LEARNING OBJECTIVES:}

1. Discuss the importance of molecular diagnostic testing in the clinical and public health laboratories.

2. Describe the origin of the polymerase chain reaction.

3. List several molecular methodologies available for diagnostic use.

ABBREVIATIONS: bDNA = Branched DNA; DNA = Deoxyribonucleic Acid; dNTP = Deoxyribonucleotides; $\mathrm{dATP}=$ Deoxyadenosine Triphosphate; $\mathrm{dCTP}=$ Deoxycytidine Triphosphate; $\mathrm{dGTP}=$ Deoxyguanosine Triphosphate; $\mathrm{dTTP}=$ Deoxythymidine Triphosphate; FDA $=$ Food and Drug Administration; FRET = Fluorescence Resonance Energy Transfer; MRSA = Methicillin Resistant Staph aureus; $\mathrm{MTB}=$ Mycobacterium tuberculosis; NASBA = Nucleic Acid Sequence Based Amplification; PCR = Polymerase Chain Reaction; PFGE = Pulsed-Field Gel Electrophoresis; RT-PCR = Reverse Transcription Polymerase Chain Reaction; Taq = Thermus aquaticus; TMA = Transcription-Mediated Amplification; VRE = Vancomycin Resistant Enterococcus.

INDEX TERMS: Molecular methodologies, PCR, Real-time PCR, Nucleic Acid Amplification

Clin Lab Sci 2010;23(4)228

Deborah Josko, PhD, M(ASCP) ${ }^{C M}$, MLT,SM, University of Medicine and Dentistry of New Jersey, Scotch Plains, NJ.

Address for correspondence: Deborah Josko, PhD $M(A S C P)^{C M}, M L T, S M$, associate professor, Department of Clinical Laboratory Sciences, Medical Laboratory Science Program, University of Medicine and Dentistry of New Jersey, 1776 Raritan Road, Scotch Plains, NJ 07076. (908)889-2422. joskotda@umdnj.edu.
One of the greatest challenges a clinical microbiologist encounters is identifying and reporting out pathogenic organisms in a timely manner. Physicians want results "stat" in order to prescribe the appropriate antimicrobial and prevent systemic spread of the infectious agent. Although the advent of automation and rapid methods has reduced turn-around times considerably, there are still fastidious organisms that may not grow well on conventional media making identification virtually impossible. These organisms can be extremely pathogenic and unless identified quickly can spread rapidly from person to person. Examples include patients infected with Mycobacterium tuberculosis (MTB), methicillin resistant Staph aureus (MRSA) and vancomycin resistant enterococcus (VRE). Fortunately, molecular diagnostic assays decrease turn around times and provide accurate and sensitive results in the identification of infectious agents. This in turn has allowed for prompt and accurate identification of pathogens, which ultimately improves patient outcomes and patient care.

Since the discovery of the DNA molecule in 1953 by James Watson and Francis Crick, the field of molecular biology has accelerated significantly, especially in the last two decades. The reason for this astonishing growth was the contribution of Dr. Kary Banks Mullis. In 1983 while driving one evening through northern California, Dr. Mullis thought of a way to amplify DNA so that billions of copies could be generated in a matter of hours. ${ }^{1}$ Dr. Mullis, who was working at Cetus Corporation in Emeryville, California at the time invented the technique called the polymerase chain reaction (PCR). PCR has revolutionized the field of molecular biology, biochemistry, and medicine and because of his astounding work and accomplishments to modern science, Dr. Mullis was awarded the Nobel Prize for Chemistry in $1993 .{ }^{1}$ 


\section{FOCUS: MOLECULAR METHODS IN CLINICAL MICROBIOLOGY}

PCR requires DNA template, target specific primers, four dNTPs (dATP, dTTP, dCTP, and dGTP), DNA polymerase, magnesium, and buffer. The original PCR method was manual and labor intensive, utilizing two separate heating blocks at different temperatures. One block was set at $95^{\circ} \mathrm{C}$, which allowed DNA strands to denature and separate into two complementary strands. The other heating block was set at $30^{\circ} \mathrm{C}$, the optimal temperature for the Klenow fragment of E. coli DNA polymerase to anneal the primers and synthesize new DNA strands. ${ }^{2,3,4}$ Unfortunately, E. coli DNA polymerase is heat labile and required the addition of new polymerase after each cycle. In 1986, a thermostable DNA polymerase called Thermus aquaticus (Taq) was identified. Taq is heat stable and need only be added once to the mix in the beginning of the reaction. ${ }^{5}$ In addition, Perkin Elmer developed the automated thermal cycler in 1988, which raises and lowers the temperature utilizing one heating block. ${ }^{6}$ Automation of PCR along with the use of Taq polymerase and other heat stable polymerases, opened the door for various modifications of the technique including the development of real-time PCR assays, reverse transcription PCR (RT-PCR), multiplex PCR, and nested PCR all commonly used in clinical laboratories, forensic laboratories, and research facilities. Although there are many molecular diagnostic methodologies available for clinical use including nucleic acid sequence based amplification (NASBA), transcription-mediated amplification (TMA), branched DNA (bDNA), hybrid capture, and cycling probe technology (all amplification techniques) as well as nucleic acid hybridization techniques, genotyping assays, and DNA probes, this series focuses on the most common molecular methodologies, instrumentation, and widely used assays in not only the clinical microbiology laboratories but the public health laboratory as well.

The first article focuses on "Molecular Virology in the Clinical Laboratory" and provides a brief overview of real time PCR including a description of the most commonly used fluorescently labeled oligonucleotides. Hydrolysis probes $\left(\operatorname{TaqMan}^{\oplus}\right)$, hybridization probes (molecular beacons), and dual hybridization probes utilizing fluorescence resonance energy transfer (FRET) are described. Since there are a considerable number of molecular assays used in clinical virology, only the most widely used FDA-cleared molecular tests and instruments (platforms) are discussed. Clinical sensitivity of each assay described are also presented. The second article concentrates on "Molecular Bacteriology in the Clinical Laboratory" and will focus on some of the more common methodologies and instrumentation utilized such as Cepheid's GeneXpert and Smart Cycler, COBAS Amplicor Analyzer and Gen-Probe. Clinical applications for identifying pathogens such as MRSA, Clostridium difficile, Neisseria gonorrhea, Chlamydia trachomatis, and MTB (to name a few) are discussed. A comparison of sensitivity and turnaround times are presented. Lastly, the third article focuses on "Molecular Diagnostics in the Public Health Laboratories" and provides an overview of some of the more common assays, both viral and bacterial, that are utilized in the identification and confirmation of pathogens such as influenza A and B, swine flu, west Nile virus, rabies, Salmonella and Shigella. Assays such as real-time PCR, pulsed field gel electrophoresis (PFGE) and multiplex PCR are discussed. A list of all FDA approved molecular assays in the identification of infectious agents both viral and bacterial are available in Addendums A and B in the online version of Clin Lab Sci 2010;23(4) at www.ascls.org.

As stated above, identifying and reporting out pathogens in a timely fashion is a challenge all microbiologists face. In the past, clinical microbiology was one of the least automated departments in the laboratory, sometimes taking days to weeks to identify fastidious organisms or organisms that are slow growers. The need for accurate, rapid and sensitive detection was essential to patient care. The use of molecular diagnostics in the clinical microbiology laboratory is expanding to the point where molecular testing is becoming part of the daily, routine workload. With more and more assays being developed, the cost behind molecular testing has decreased since there are more competitors on the market. At one point, clinical microbiologists thought of routine molecular testing as the wave of the future. It is obvious the future is upon us. Molecular diagnostic testing in the clinical microbiology laboratory will only escalate as technology continues to grow and new methods become available for use. 


\section{FOCUS: MOLECULAR METHODS IN CLINICAL MICROBIOLOGY}

Author's Note: The intent of this Focus Section is to introduce medical laboratory scientists and educators to some of the common molecular diagnostic assays and platforms available. It is in no way an endorsement for any particular company or product and the author has no financial gain or otherwise interest in the products presented. This series of articles is for educational and informational purposes only. The assays and instrumentation highlighted in these three articles are the result of consultation with several laboratorians in the clinical and Public Health Laboratories in New Jersey to determine which products are commonly used.

\section{REFERENCES}

1. Mullis KB. Autobiography. From Les Prix Nobel. The Nobel Prizes 1993, Editor Tore Frängsmyr, [Nobel Foundation], Stockholm, 1994.
2. Mullis KB, Faloona FA, Scharf S, et al. Specific enzymatic amplification of DNA in vitro: the polymerase chain reaction. Cold Spring Harbor Symp Quant Biol 1986;51:263-73.

3. Mullis KB, Faloona FA. Specific synthesis of DNA in vitro via a polymerase-catalyzed chain reaction. Methods Enzymol 1987; $155: 335-50$.

4. Mullis KB. The unusual origin of the polymerase chain reaction. Scientific American 1990; 262:56-65.

5. Tindall KR, Kunkel TA. Fidelity of DNA synthesis by the Thermus aquaticus DNA polymerase. Biochem 1998;27:600813.

6. US Patent 5602756: Thermal cycler for automatic performance of the polymerase chain reaction with close temperature control. Available from http://www.patentstorm. us/patents/5602756.html. Accessed 2010 April 14.

7. Mahon CR, Lehman DC, Manuselis G, editors. Textbook of Diagnostic Microbiology. $4^{\text {th }}$ ed. Missouri: Saunders Elsevier; 2011.

The Focus section seeks to publish relevant and timely continuing education for clinical laboratory practitioners. Section editors, topics, and authors are selected in advance to cover current areas of interest in each discipline. Readers can obtain continuing education credit (CE) through P.A.C.E. by completing the continuing education registration form, recording answers to the examination, and mailing a photocopy of it with the appropriate fee to the address designated on the form. Suggestions for future Focus topics and authors, and manuscripts appropriate for CE credit are encouraged. Direct all inquiries to the Clin Lab Sci Editorial Office, Westminster Publishers, 315 Westminster Court, Brandon MS 39047. (601) 214-5028, (202) 315-5843 (fax).westminsterpublishers@comcast.net. 